\title{
Computed tomography and psychometric test performances in patients with solvent induced chronic toxic encephalopathy and healthy controls
}

\author{
P ØRBÆK, ${ }^{1}$ MAY LINDGREN, ${ }^{2}$ H OLIVECRONA,$^{3}$ BIRGITTA H ÆGER-ARONSEN ${ }^{1}$
}

From the Department of Occupational Medicine, ${ }^{1}$ Malmö General Hospital, Malmö, Department of Psychiatry, ${ }^{2}$ Lund University Hospital, Lund, and Department of Radiology, ${ }^{3}$ Malmö General Hospital, Malmö, Sweden

\begin{abstract}
Patients with chronic toxic encephalopathy caused by occupational exposure to organic solvents and diagnosed between 1976 and 1981 have been re-examined during a follow up period of 21-88 months (median 48). Thirty two patients underwent computed brain tomography (CT), were retested psychometrically, and the results were compared with a group of age matched control subjects from the same socioeconomic level. The age of the patients was 33-69 (median 55) and they had been exposed to organic solvents for 7-50 years (median 26). The CT examinations were quantified by linear measurements on the films of the four largest sulci, the minimum width of the cella media and the third ventricle. Bifrontal horn, bicaudate, and third ventricle-Sylvian fissure distances were also measured; and measurements were adjusted for variation in skull diameter. No differences were found between the patients and controls. Most of the measures were correlated with age, to a somewhat higher degree in the patients. The patient-control differences did not increase with increasing age of the subjects. Psychometrically the patients performed worse than the controls despite adjustments for possible differences of intellectual level in the two groups. In the patients correlations were found between some of the CT measures and psychometric test performances suggesting slower psychomotor speed and attention difficulties among subjects with central and cortical brain substance reduction. No such correlation was found in the control group. It is concluded that patients with solvent induced chronic toxic encephalopathy have no severe loss of brain substance.
\end{abstract}

Long term exposure to organic solvents as a cause of chronic toxic encephalopathy now seems well established; the World Health Organisation has recently published recommendations on this matter ${ }^{1}$ and definition of the syndrome has been suggested at a conference in the United States. ${ }^{2}$

One unresolved question is how solvent induced toxic encephalopathy differs from disorders leading to presenile dementia such as Alzheimer's and Pick's discases. Patients with these diseases suffer from progressive brain disease with neuronal death, which may be detected by use of computed tomography (CT) and regional cerebral blood flow (rCBF) determinations. ${ }^{34}$ These methods usually show brain atrophy and reduced cerebral blood flow as signs of death of the neuron which may be finally shown at necropsy. Studies on patients with solvent induced toxic

Accepted 27 August 1986 encephalopathy using pneumoencephalography and computed tomography have also disclosed brain atrophy among these patients. ${ }^{5-7}$ Quantification of brain atrophy in demented patients has been performed by linear measurements on CT films $\mathrm{s}^{8-10}$ and the degree of brain atrophy has been shown to correlate with performance in psychometric tests. ${ }^{11-14}$

The aims of the present study were to examine solvent exposed encephalopathic patients by computed tomography, to search for signs of cerebral atrophy, and to investigate possible correlations between CT measures and psychometric test performances.

\section{Subjects}

From 1976 to 1981,62 patients were given a diagnosis of solvent induced chronic toxic encephalopathy. The diagnosis was based on neuraesthenic symptoms and abnormal performance in psychometric tests pre- 
ceded by substantial exposure to organic solvents (preferably daily for more than ten years). Computed tomography was not used in arriving at the diagnosis.

Every second year the patients underwent further examinations and tests. To rule out other causes of brain dysfunction among the subjects selected for the study, we have strictly excluded patients with any of the following: severe head trauma, cerebrovascular manifestations, other neurological disorders, diffuse arteriosclerotic signs, alcohol and drug abuse, and any severe psychiatric or somatic disease.

The differential diagnostic evaluation comprised extensive neurological examination, computed EEG power spectrum analyses (I Rosén, unpublished observations), measurements of rCBF (S Hagstadius, unpublished observations), clinical chemistry, examination of all available hospital files, and a social evaluation carried out by our social worker with interviews in the patients' homes. Using clinical chemistry, we have checked the patients for syphilis; thyroid and parathyroid gland function $\left(\mathrm{T}_{3}, \mathrm{TSH}\right.$, $\mathrm{S}$-Calcium); kidney and liver function (creatinine, electrolytes, and enzymes); malabsorption ( $\mathbf{B}_{12}$, folate); and inflammatory disease (blood cells, haemoglobin, and erythrocyte sedimentation rate).

The main study group (group 1) of patients with diagnosed chronic toxic encephalopathy comprised 32 men aged 33-69 (median 55). They were diagnosed 21-88 months (median 48) before the study began and were no longer exposed to solvents. Before seeking help for their neuraesthenic and affective symptoms they had been exposed daily to solvents for 7-50 years (median 26). According to the classification suggested in the United States they had a type $2 \mathrm{~b}$ syndrome ${ }^{2}$; their occupations are listed in table 1. Alcohol consumption was less than $200 \mathrm{~g} / \mathrm{w}$ for 26 subjects and no more than $400 \mathrm{~g} / \mathrm{w}$ for the remaining six. Nine subjects used CNS active drugs, mostly minor tranquilisers, and nine were taking regular medication; 15 did not use drugs regularly.

During the follow up we diagnosed 13 of the 62 subjects as having other diseases which might interfere with the solvent effects on their brain function (see table 2). Five of these subjects and three with suspected brain disease underwent $\mathrm{CT}$ before being

Table 1 Occupations of patients with chronic toxic encephalopathy

\begin{tabular}{lr}
\hline & No \\
\hline Industrial spray painters & 8 \\
Car repair spray painters & 7 \\
House painters & 5 \\
Paint industry workers & 5 \\
Floor layers & 2 \\
Others & 5 \\
\hline
\end{tabular}

Table 2 Diagnoses of subjects excluded during follow up or during the study.

\author{
Excluded during follow up: \\ Cerebral arteriosclerosis $(n=2)$ \\ Progressive neurological disease \\ Cyclic depression \\ Grand mal epilepsy \\ Alcoholism $(\mathrm{n}=2)$ \\ Lung cancer \\ Excluded during the study but underwent CT (group 2): \\ Severe polyarteritis \\ Parkinsonism and cerebral infarction \\ Pituitary adenoma \\ Alcoholism (two with polyneuropathy only) $(n=4)$ \\ Colon cancer (polyneuropathy only)
}

excluded; these eight subjects will be referred to as group 2. They were aged 34-64 (median 57).

Seventeen of the patients did not accept complete follow up and CT. Three were alcoholics and one had lung cancer (as listed in table 2). The remaining 13 o were comparable with group 1 with respect to sex, age, exposure, symptoms, and test results.

The control group consisted of 40 age matched men from the same socioeconomic level as the study group. They had never been exposed to solvents and all were in good health. For the comparison of psychometric test results, only group 1 and their controls were used. Fifteen of the controls had been tested previously ${ }^{15}$; the remaining 17 (who were older) were tested during the present study.

\section{Methods}

Computed tomography was performed on a Siemens Somatom 2, the neuroradiologist being blind as to the subjects' diagnosis. The four largest sulci and the minimum width of the cella media were measured directly on the films (figure). In addition the bifrontal horn and bicaudate distances, the minimal width of the third ventricle, and the distances from the third ventricle to the Sylvian fissures on both sides were also measured (figure).

A cortical index was calculated as the sum of the four sulcal measures. Adjustments for variation of skull size were made by calculating the ratios of the bifrontal horn, bicaudate, and the sum of the third ventricle-Sylvian fissure distances divided by the largest skull diameter. These ratios are called Evan's, N bicaudate, and 3V-Sylvian fissure (3V-SF) indices, respectively.

Psychometrically the patients and control subjects were examined using tests of logical inductive abilities (Koh's block design and figure classification ${ }^{16}$ ), spatial memory (Benton visual retention test, GrahamKendall's memory for design test), verbal abilities (synonyms), and verbal memory (paired associates). Further tests explored psychomotoric abilities (reac- 

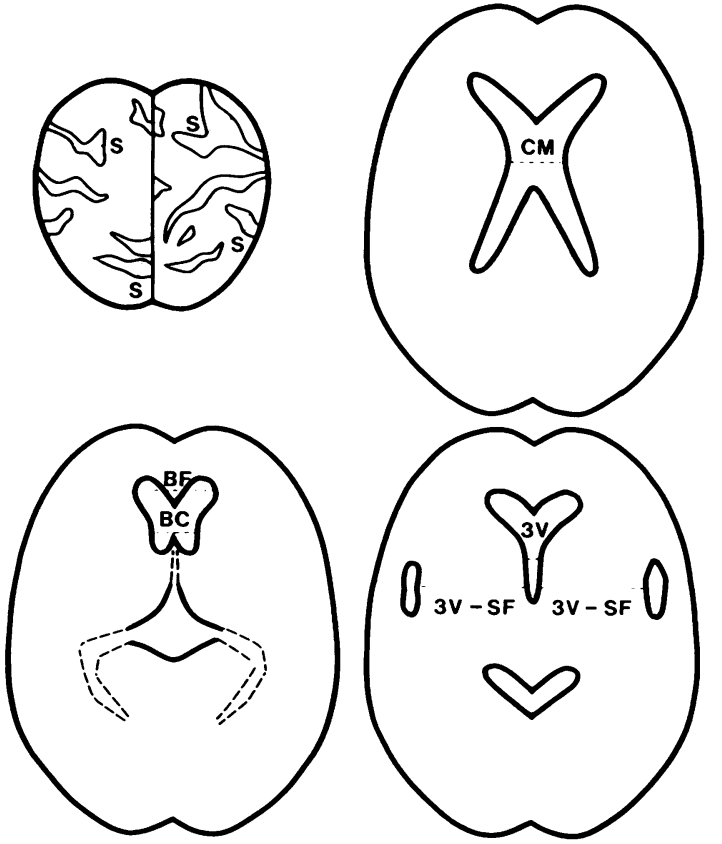

Linear measurements on various $C T$ sections: four largest sulci $(S)$; minimum width of cella media $(C M)$; bifrontal horn distance $(B F)$; hicaudate distance $(B C)$; minimum width of third ventricle $(3 V)$; distance from third ventricle to Sylvian fissure $(3 V-S F)$.

tion time test, simple and multiple choice, Pintest, and Santa Ana dexterity test), perceptual ability (digit symbol), intellectual flexibility (colour word test ${ }^{17}$ as used in this study) and sustained focused attention capabilities (dots).

For a description of the tests see Ørbæk et al. ${ }^{15}$ The results of pintest and Santa Ana dexterity test have been pooled and are referred to as the hand motor test because of varying test use at the patients' first test session. In the reaction time tests subjects are missing because of equipment failure.

Two tests, synonyms and figure classification, have been used as hold tests. Synonyms is traditionally known to be resistant to the effects of small brain lesions. During the follow up period the performance of the patients in this test declined, but the difference was not statistically significant as it was in the verbal memory test paired associates. ${ }^{18}$ For this reason we also considered the figure classification test, a nonverbal hold test in which no change in performance was found during follow up, to be an indicator of group comparability.

Statistics were calculated with the use of the program package, New Mathematical Statistics Package. Analysis of variance was used for comparisons of the measurements on the CT films among the three
Table 3 Results of measurements on computed brain tomography films and age correlation coefficients or $p$ values for the analysis of variance between the three groups

\begin{tabular}{|c|c|c|c|c|}
\hline & Mean & $S D$ & $r$ & $p$ \\
\hline \multicolumn{5}{|l|}{ Cortical index $(\mathrm{mm})$ : } \\
\hline Controls $(n=40)$ & $4 \cdot 3$ & $1 \cdot 1$ & $0.41^{* *}$ & \multirow[b]{3}{*}{0.41} \\
\hline Group I $(n=32)$ & $4 \cdot 5$ & 1.6 & $0 \cdot 48^{* *}$ & \\
\hline Group $2(n=8)$ & 4.9 & 1.6 & & \\
\hline \multicolumn{5}{|c|}{ Cella media (min width $\mathrm{mm}$ ): } \\
\hline Controls $(n=40)$ & $7 \cdot 1$ & $1 \cdot 1$ & $0 \cdot 30$ & \multirow[b]{3}{*}{0.68} \\
\hline Group I $(\mathrm{n}=32)$ & 7.0 & $1 \cdot 3$ & $0.40^{*}$ & \\
\hline Group $2(n=8)$ & $6 \cdot 8$ & $1 \cdot 2$ & & \\
\hline \multicolumn{5}{|c|}{ 3rd ventricle ( $\max$ width $\mathrm{mm}$ ): } \\
\hline Controls $(n=40)$ & 1.2 & 0.4 & $0 \cdot 20$ & \multirow[b]{3}{*}{0.48} \\
\hline Group I $(\mathrm{n}=32)$ & 1.1 & $0 \cdot 3$ & $0.48^{* *}$ & \\
\hline Group $2(n=8)$ & $1 \cdot 3$ & 0.5 & & \\
\hline \multicolumn{5}{|l|}{ Evan's index: } \\
\hline Controls $(n=40)$ & 0.280 & 0.023 & 0.26 & \multirow[b]{3}{*}{0.79} \\
\hline Group I $(n=32)$ & 0.278 & 0.027 & $0.37^{*}$ & \\
\hline Group $2(n=8)$ & 0.274 & 0.028 & & \\
\hline \multicolumn{5}{|l|}{ Bicaudate index: } \\
\hline Controls $(n=40)$ & 0.121 & 0.023 & $0 \cdot 46^{* *}$ & \multirow[b]{3}{*}{0.82} \\
\hline Group I $(n=32)$ & 0.118 & 0.020 & $0 \cdot 32$ & \\
\hline Group $2(n=8)$ & 0.117 & 0.023 & & \\
\hline \multicolumn{5}{|c|}{ 3V-Sylvian fissure index: } \\
\hline Controls $(n=40)$ & 0.626 & 0.031 & $\begin{array}{l}-0.17 \\
-0.24\end{array}$ & \\
\hline $\begin{array}{l}\text { Group } 1(n=32) \\
\text { Group } 2(n=8)\end{array}$ & $\begin{array}{l}0.625 \\
0.617\end{array}$ & $\begin{array}{l}0.036 \\
0.033\end{array}$ & & 0.78 \\
\hline
\end{tabular}

groups. Age adjusted partial correlation coefficients were calculated between the CT measures and the psychometric test results. Hotelling's T test was used for multivariate group comparison. Wilcoxon rank sum test was used for comparisons of the psychometric test results. A multiple linear regression model has been used for adjustment of the difference between the groups in the hold tests.

\section{Results}

Table 3 shows the results of the measurements on the CT films. No statistically significant differences were found between the group with chronic toxic encephalopathy and the control group. Multivariate comparison using Hotelling's $T$ test confirmed this conclusion.

As seen in table 3, most CT measures were age dependent. With the hypothesis that aging in the brain is accelerated by exposure to solvents, the differences between the CT measures for solvent exposed and matched control subjects were calculated and the correlation with age was tested. The correlations were small and gave no support to the hypothesis stated; "Evan's index" $r=0.08$, "bicaudate index" $r=-0.08, " 3 \mathrm{~V}-\mathrm{SF}$ index" $r=0.02$, "cortical index" $r=0 \cdot 12$.

Psychometric test performance was, as expected, generally lower in the group of patients with chronic solvent encephalopathy (see table 4). Adjustments for the performance differences in figure classification 
Table 4 Psychometric raw scores for patients with toxic encephalopathy (group 1) $(n=32)$ and age matched controls $(n=32)$. p Values for the group comparisons with Wilcoxon rank sum test. $Q I=$ low'er quartile, $Q 3=$ upper quartile

\begin{tabular}{|c|c|c|c|c|}
\hline & $Q I$ & Median & $Q 3$ & $p$ \\
\hline \multicolumn{5}{|l|}{ Synonyms (SR B:1): } \\
\hline Controls & 22 & 25 & 27 & \multirow[t]{2}{*}{0.00003} \\
\hline Group 1 & 11 & 18 & 21 & \\
\hline \multicolumn{5}{|c|}{ Figure classification (SRB:2): } \\
\hline $\begin{array}{l}\text { Controls } \\
\text { Group I }\end{array}$ & $\begin{array}{l}17 \cdot 75 \\
14 \cdot 50\end{array}$ & $\begin{array}{l}22 \cdot 50 \\
20 \cdot 00\end{array}$ & $\begin{array}{l}24 \cdot 50 \\
22 \cdot 50\end{array}$ & \multirow[t]{2}{*}{$0 \cdot 10$} \\
\hline \multicolumn{4}{|l|}{ Block design (SR B:3): } & \\
\hline Controls & 22 & 28 & 31 & \multirow[t]{2}{*}{0.003} \\
\hline Group 1 & 14 & 21 & 27 & \\
\hline \multicolumn{5}{|c|}{ Benton visual retention test, correct: } \\
\hline Controls & 6 & 7 & 9 & \multirow{2}{*}{0.011} \\
\hline Group 1 & 4 & 6 & 8 & \\
\hline \multicolumn{5}{|c|}{ Benton visual retention test, errors: } \\
\hline Controls & 2 & 3 & 7 & \multirow[t]{2}{*}{0.026} \\
\hline Group 1 & 3 & 5 & 8 & \\
\hline \multicolumn{5}{|c|}{ Graham-Kendall memory for design: } \\
\hline Controls $(n=17)$ & 0 & 1 & 2 & \multirow{2}{*}{0.12} \\
\hline Group 1 & 0 & 3 & 8 & \\
\hline \multicolumn{5}{|l|}{ Paired associates: } \\
\hline Controls & 16 & 21 & 24 & \multirow[t]{2}{*}{0.00000} \\
\hline Group 1 & 10 & 12 & 16 & \\
\hline \multicolumn{5}{|l|}{ Colour word test: } \\
\hline Controls & 110 & 126 & 150 & \multirow[t]{2}{*}{0.020} \\
\hline Group 1 & 125 & 153 & 187 & \\
\hline \multicolumn{5}{|l|}{ Digit symbol: } \\
\hline $\begin{array}{l}\text { Controls } \\
\text { Group I }\end{array}$ & 39 & 45 & 53 & \multirow[t]{2}{*}{0.0008} \\
\hline $\begin{array}{l}\text { Group I } \\
\text { Dots, total time: }\end{array}$ & 25 & 32 & 44 & \\
\hline \multicolumn{5}{|l|}{ Dots, total time: } \\
\hline Group 1 & 420 & 480 & 570 & 0.0025 \\
\hline \multicolumn{5}{|c|}{ Dots, time fluctuation: } \\
\hline Controls & 15 & 18 & 21 & \multirow[t]{2}{*}{0.00002} \\
\hline Group 1 & 21 & 34 & 46 & \\
\hline \multicolumn{5}{|l|}{ Dots, errors: } \\
\hline Controls & 6 & 12 & 18 & \multirow[t]{2}{*}{$0 \cdot 23$} \\
\hline Group 1 & 6 & 16 & 32 & \\
\hline Dots, error fluctuatio & & & & \\
\hline Controls & 4 & 8 & 10 & $0 \cdot 67$ \\
\hline Group 1 & 4 & 7 & 14 & \\
\hline Simple reaction time s & $\times 10^{-2}:$ & & & \\
\hline Controls $(\mathrm{n}=16)$ & $39 \cdot 8$ & $43 \cdot 6$ & $47 \cdot 6$ & 0.008 \\
\hline $\begin{array}{l}\text { Group I }(n=28) \\
\text { Reaction time multipl }\end{array}$ & $\begin{array}{l}44 \cdot 2 \\
\text { choice s }\end{array}$ & $\begin{array}{r}56 \cdot 1 \\
10^{-2}\end{array}$ & $64 \cdot 4$ & \\
\hline Controls $(n=16)$ & 43.7 & $47 \cdot i$ & $52 \cdot 9$ & 0.0003 \\
\hline Group $1(n=28)$ & $50 \cdot 5$ & 61.9 & $83 \cdot 4$ & \\
\hline Hand motor test (stan & ine score & & & \\
\hline $\begin{array}{l}\text { Controls } \\
\text { Group 1 }\end{array}$ & 3 & 4 & 6 & 0.0001 \\
\hline Group I & 1 & 2 & 4 & \\
\hline
\end{tabular}

Table 5 Statistically significant correlations between $C T$ measures and psychometric test results and the partial correlation adjusted for age. ${ }^{*} p<0.05,{ }^{* *} p<0.01$, ${ }^{* * *} p<0.001$ for the correlation coefficient

\begin{tabular}{|c|c|c|c|}
\hline CT measure & Test & Pearson $r$ & $\begin{array}{l}\text { Age adjusted } \\
\text { correlation }\end{array}$ \\
\hline \multicolumn{4}{|c|}{$\begin{array}{ll}\text { Chronic toxic encephalopathy group I } \\
\text { Evan's index } & \text { Block design } \\
\text { Evan's index } & \text { Dots total time } \\
\text { 3V-SF index } & \text { Figure classification } \\
3 \mathrm{~V}-\mathrm{SF} \text { index } & \text { Dots fluctuation }\end{array}$} \\
\hline \multicolumn{4}{|c|}{$\begin{array}{l}\text { Control group ( } n=32) \\
\text { No significant correlation }\end{array}$} \\
\hline
\end{tabular}

and synonyms were carried out by multiple linear regression analyses with test score and group as independent variables. After adjustment for the score in figure classification the group differences became smaller and not statistically significant in the following tests: Benton visual retention test errors and colour word test. When the score in synonyms was used for adjustment, the group differences disappeared in the following tests: block design, Benton visual retention test correct and errors, and colour word test. Scores in dots and the hand motor test were not dependent on the hold test scores.

In the group with toxic encephalopathy some CT measures correlated with psychometric test results even after adjustment for possible age covariation (table 5). In the control group no such correlations were found.

\section{Discussion}

We have been restrictive in selecting subjects for this study since our purpose was to eliminate the influence of other diseases on the brain and on the subjects' psychometric test performance. The loss of 13 patients during follow up does not appear to influence the validity of the study. These 13 subjects were, so far as we know, comparable with the 32 subjects discussed here.

The appearance of other diseases in a group primarily diagnosed as having chronic toxic encephalopathy is to be expected, judging from previous reports on the re-examination of patients with dementia ${ }^{1920}$ and also from reports on the prognosis of toxic encephalopathy. ${ }^{2122}$ The Swedish compensation rules allow the primary diagnosis to be made more freely, with respect to aetiology, than in a study of the pure solvent effects.

We are unable to confirm the results of ArlienSøborg et al on the computed tomography findings in patients with toxic encephalopathy. ${ }^{5}$ Recently, Lauritsen et al reported inconsistent observations on brain CT in a follow up study on solvent exposed workers. ${ }^{23}$ Our results seem to agree with this and with those obtained in cross sectional studies on solvent exposed workers ${ }^{24}$ (G Triebig, unpublished observations).

The methods used in the present study to quantify the CT may not be optimal ${ }^{1314}$ but we find them sensitive enough to show differences between the groups examined. It is important to realise that toxic encephalopathy does not necessarily mean neuronal death or loss of brain substance.

The large difference in the synonyms score suggests a higher intellectual level among the controls than among the patients. This influences the performance in the other tests and rematching on this factor has 
been shown to eliminate apparent group differences. ${ }^{25}$ The performance of the encephalopathic patients in verbal tests declined during the follow up period, ${ }^{18}$ which suggested the need of a non-verbal hold test as well.

For controlling the possible differences in intelligence between the two groups, we have made adjustments to equal the scoring in the two hold tests statistically. The group with chronic toxic encephalopathy scored less well than the control group in a substantial part of the test battery even after this adjustment.

In groups of alcoholics and patients with presenile dementia measurements on CT films correlate with psychometric test performance. ${ }^{121426}$ This is also the case in our group of patients with chronic toxic encephalopathy. No correlation was found in the control group, which is in agreement with the results from an investigation of a sample from the general population. ${ }^{26}$ We do not have an explanation for this observation, but it suggests some change of brain function in the solvent exposed subjects. The number of statistical computations gives, however, an expectation of several significant correlations by pure chance. The negative correlation between the $3 \mathrm{~V}-\mathrm{SF}$ index and the figure classification test seems especially to lack plausibility. The three other statistically significant correlations are plausible and indicate slower psychomotor speed and problems with attention in the subjects with a reduction in the central and cortical brain substance.

A calculation of any exposure effect relation was impossible. Elaborate exposure indices would inevitably be highly correlated with age, and the discrimination between age and the possible effects of exposure would be tentative in this type of study. The more pronounced age effect on the CT measures in the patient group might, however, suggest an effect of exposure.

We conclude that the patients with solvent induced chronic toxic encephalopathy had neuraesthenic and affective symptoms and performed more poorly than controls in psychometric tests but they had no signs of brain atrophy in CT.

We thank psychologist Sten Rehnström for testing some of the controls and statistician Lars Wahlgren for discussion and advice. The study was supported by the Swedish Work Environment fund by grant ASF 82-1011 and by Folksam Yrkesskador Stiftelse. Ms Kirsten Åberg helped with the drawings in the figure.

\section{References}

I World Health Organisation. Chronic effects of organic solvents on the central nervous system and diagnostic criteria. Copenhagen WHO, 1985. (Environmental health 5.)

2 Waldron HA. Solvents and the brain. Br J Ind Med 1986;43:73-4.

3 Wells CE. Chronic brain disease: an overview. Am J Psychiatry 1978:135:1-12

4 Risberg J. Gustafson L. 133-Xe cerebral flow in dementia and in neuropsychiatry research. In: Magistretti PL, ed. Functional radionuclide imaging of the brain. New York: Raven Press, 1983:151-60.

5 Arlien-Søborg P, Bruhn P, Gyldenstedt C, Melgaard B. Chronic painters' syndrome. Chronic toxic encephalopathy in house painters. Acta Neurol Scand 1979;60:149-56.

6 Juntunen J, Hernberg S, Eistola P, Hupli V. Exposure to organic solvents and brain atrophy. A retrospective study of pneumoencephalographic findings among 37 patients with exposure to industrial solvents. Eur Neurol 1980;19:366-75.

7 Jensen PB, Nielsen P, Nielsen NO, Olivarius BdeF, Hansen JH. Chronic toxic encephalopathy following occupational exposure to organic solvents. The course after cessation of exposure illustrated by a neurophysiological follow-up investigation. Ugeskr Laeg 1984;146:1387-90.

8 Fox IH, Topel IL, Huckman MS. Use of computerised tomography in senile dementia. $J$ Neurol Neurosurg Psychiatry 1975;38:948-53.

9 Gyldenstedt C. Measurements of the normal ventricular system and hemispheric sulci of 100 adults with computed tomography. Neuroradiology 1977;14:183-92.

10 Jacoby R, Levy R. CT scanning and the investigation of dementia: a review. $J R$ Soc Med 1980;73:366-9.

11 Willanger R, Thygesen P, Nielsen R, Pedersen O. Intellectual impairment and cerebral atrophy. A psychological, neurological and radiological investigation. Dan Med Bull 1968;15:65-93.

12 Brinkman SD, Sarwar M, Levin HS, Morris HH. Quantitative indexes of computed tomography in dementia and normal aging. Radiology 1981;138:89-92.

13 Eslinger PJ, Damasio H, Graff-Radford N, Damasio A. Examining the relationship between computed tomography and neuropsychological measures in normal and demented elderly. J Neurol Neurosurg Psychiatry 1984;47:1319-25.

14 Gebhardt CA, Naeser MA, Butters N. Computerized measures of CT scans of alcoholics: thalamic region related to memory. Alcohol 1984;1:133-40.

15 Ørbæk P, Risberg J, Rosén I, et al. Effects of long-term exposure to solvents in the paint industry. A cross-sectional epidemiologic study with clinical and laboratory methods. Scand $J$ Work Environ Health 1985;11(suppl 2):1-28.

16 Dureman I, Kebbon L, Österberg E. Manual til DS-batteriet. Stockholm: Psykologiförlaget, 1971.

17 Kragh IU, Smith GJW. Percept-genetic analysis. Lund: Gleerup, 1970.

18 Ørbæk P, Lindgren M. Prospektiv psykometrisk undersökning av patienter med lösningsmedelsbetingat organiskt psykosyndrom. Läkartidningen 1986;83:2647-51.

19 Marsden CD, Harrison MJG. Outcome of investigation of patients with presenile dementia. Br Med J 1972;ii:242-52.

20 Smith JS, Kiloh LG, Ratnavale GS, Grant DA. The investigation of dementia. The results in 100 consecutive admissions. Med $J$ Aust 1976;2:403-5.

21 Arlien-Søborg P, Bruhn P, Christensen EL, Gyldenstedt C, Damgaard M. Chronic painters' disease. A follow-up investigation of 26 former house painters with occupational toxic encephalopathy. Ugeskr Laeg 1981;143:3069-74.

22 Juntunen J, Antti-Poika M, Tola S, Partanen T. Clinical prognosis of patients with diagnosed chronic solvent intoxication. Acta Neurol Scand 1982;65:488-503.

23 Lauritsen J, Gade A, Viskum P. Occupational toxic encephalopathy. Follow-up investigations of a material from a clinic for occupational medicine. Ugeskr Laeg 1985;147:3727-33.

24 Elofsson SA, Gamberale F, Hindmarsh T, et al. Exposure to organic solvents: a cross-sectional epidemiologic investigation on occupationally exposed car and industrial spray painters with special reference to the nervous system. Scand J Work Environ Health 1980;6:239-73.

25 Cherry N, Hutchins H, Pace T, Waldron HA. Neurobehavioural effects of repeated occupational exposure to toluene and paint solvents. Br J Ind Med 1985;42:291-300.

26 Bergman H, Borg S, Hindmarsh T, Ideström CM, Mützell S Computed tomography of the brain and neuropsychological assessment of male alcoholic patients and a random sample from the general male population. Acta Psychiat Scand 1980:62(suppl 286):77-88. 